\title{
Violence toward Nurses Working in Family Health Care Centers in Alexandria and El Behera Governorates
}

\author{
Rasha Abd El Hakim Abdou, Lecturer \\ Community Health Nursing, Faculty of Nursing, Alexandria University \\ Doaa Abd EI Salam Amin, Lecturer \\ Community Health Nursing, Faculty of Nursing, Damanhour University
}

\begin{abstract}
Work place violence against health care workers is a common and widespread phenomenon. There is an increased evidence that nursing staff is at such a high risk of exposure to violent behaviors in their work place. Objective: To assess, compare work place violence toward nurses working in family health care centers in Alexandria and El Behera Governorate and identify its related risk factors. Settings: The study was carried out four health centers in Alexandria and eight health centers in El Behera governorate giving a total number of 12 family health care centers. Subjects: 80 nurses from Alexandria governorate and 120 from El Behera governorate giving a total number of 200 nurses. Tool: One tool was used for data collection namely work place violence questionnaire which includes nurses' demographic data, characteristics of workplace violence events, and risk factors contributing to workplace violence. Results: Findings of the present study revealed that $78.8 \%$ of nurses in Alexandria compared to $73.3 \%$ of nurses in El Behera reported exposure to violence in the last year. Conclusion: The study concluded that a significant proportion of nurses faced violence while providing care in urban and rural primary health facilities. Being a staff nurse, of younger age, and short work experience were significantly associated with workplace violence. Recommendations: Workplace violence prevention strategies are needed to make health care settings a safe environment.
\end{abstract}

Keywords: Workplace violence, Health care workers, Nurses.

\section{Introduction}

Violence is one of the most prevailing, complex and dangerous occupational hazards facing health care workers especially when directed to nurses. The real size of the problem is largely unknown and recent information shows that the current knowledge is only the tip of the ice $\operatorname{berg}^{(1)}$. However, recent studies indicate that as much as $90 \%$ of health care workers have experienced violent incidents at work, with percentage ranging from $70-80 \%$ for nurses $^{(2,3)}$. The actual prevalence of violence against health care workers is unknown because there is no stander definition on what constitutes a violent incident in health care settings ${ }^{(4)}$.
As violence in health care settings attains special concern, World Health Organization (WHO) has defined it as any verbal, non verbal or physical behavior that is threatening or cause harm to health care workers or to their properties ${ }^{(5,6)}$.

There is an increased evidence that nursing staff is at such a high risk of exposure to violent behaviors in their work place $^{(7)}$. Nurses have the closest contact with patients and their relatives, who may have a reduced capacity to control their behaviors and express themselves through aggression due to extreme disease, injury, stress and other induced changes ${ }^{(8)}$.

Many risk factors may contribute to the development of violent behavior 
including the characteristics of perpetrators, health care providers, health organization, and environment. The perpetrators' characteristics include their age, gender, mental state and past history of aggression. Similarly, health care providers' characteristics include their gender, age, years of experience in health care sector, occupation and education. Organizational factors include understaffing, working hours and the nature of work within the health facility, while environmental factors may include poor physical infrastructure of the workplace and limited violence preventive strategies $^{(9-11)}$.

The consequences of work place violence can be devastating, not only for the nurse, but also for the perpetrator as well as for the community in large. Nurses' exposure to abuse while carrying out their duties adversely affects nurses and may lead to loss of concentration while performing their tasks, higher numbers of careless mistakes, repeated absenteeism, reduction in job satisfaction, dislike of their job, and refusal to work in stressful wards. These may have greater implications for the health organization with respect to staff turnover, retention and poor quality of services rendered $^{(2,8)}$.

High risk practice settings were thought to be almost exclusively acute care settings, emergency department and critical care units, as they still constitute particularly hot spots for violence. However, recent studies now also point to violence against nurses in various community health care settings such as family health care centers and nursing homes $^{(12,13)}$.

Given the importance of the problem of work place violence and the fact that there are few data on violence against nurses working in primary health care settings, this study was conducted to determine the prevalence and types of violence towards nurses. Such information will be useful in understanding the source of violence against nurses and identifying factors that contribute to workplace violence as well as developing effective methods to reduce such problem in healthcare settings. This research has implication not only for nurses' health and safety but also, in the broader sense, for the profession's ability to attract and retain nurses within the health care system.

\section{Aims of the Study}

1. Assess work place violence toward nurses working in family health care centers in Alexandria and El Behera Governorate.

2. Compare between work place violence exposure toward nurses working in family health care centers in Alexandria and Behera Governorate.

3. Identify work place violence related risk factors toward nurses working in family health care centers in Alexandria and Behera Governorate.

\section{Research Questions:}

1. Is there a difference between nurses working in family health care centers in Alexandria and El Behera Governorate in relation to violence exposure?

2. What are the violence related risk factors toward nurses working in family health care centers in Alexandria and El Behera Governorate?

\section{Materials and Method}

\section{Materials}

Design: The descriptive comparative design was adopted to carry out this study.

Settings: The study was conducted in two governorates; Alexandria and El Behera governorates. Multistage sampling 
technique was used to select study settings as follow:

- Alexandria governorate was divided into 8 health zones namely El Montaza, East, Middle, West, El Gomerk, El Ameria, El Agamy, and Borg El Arab. While El Behera governorate was divided into 16 health zones namely ; Edco, Rosetta, Abo El Matameer, Househ Esa, El Delingate, El Tahreer, West El Noubarya, El Natroon Valley, Damanhur, Abo Homous, Kafr El Dawar, El Mahmodya, El Rahmanya, Shoubra kheit, Kom Hamada and Itay El Baroud.

- Using the proportional allocation method a random sample of $50 \%$ of health zones in Alexandria and El Behera governorate were selected. Four health zones in Alexandria and Eight health zones in El Behera governorate. The total number was 12 health zones.

- Using the equal allocation method one family health care center was randomly selected from each of the previously chosen health zones in Alexandria and El Behera governorate. Four centers in Alexandria and Eight centers in El Behera governorate giving a total number of 12 Family health care centers.

Subjects: All available and assigned nurses in the previously selected family health centers were included in the study. This was given a total number of 200 nurses ( 80 from Alexandria governorate and 120 from El Behera governorate).

Tool: In order to collect the necessary data for the study one tool was used:

\section{Tool I: Violence Questionnaire}

It was developed by the researchers to collect the necessary data from nurses after reviewing of recent literatures ${ }^{(1,2,4,12,14)}$. It included three parts:

First Part: Nurses' personal and sociodemographic data: It included the age, sex marital status, educational qualifications, current job, position and years of experiences.
Second Part: Work place data: It included data about the working shift, availability of work place violence preventive strategies such as policies, training programs and safety measures.

Third Part: Exposure to work place violence data: It comprises data about actual exposure to work place violence incident. It included type of violence, its source, causes of work place violence from their point of views, time of exposure, reactions to violence incident and nurses' suggestions to reduce exposure to work place violence.

\section{Method}

- Approval of responsible authorities was obtained through official letters from the Faculty of Nursing.

- Meetings were held with the directors of the selected settings to clarify the purpose of the study and to gain their cooperation and support during data collection.

- The study tool was developed by the researchers after reviewing the recent relevant literature. It was validated by juries of (3) experts in the field. Their suggestions and recommendations were taken into consideration.

- Cronbach Alpha Coefficient was used to ascertain the reliability of the tool $(r=0.86)$.

- Pilot study was carried out on 20 nurses who were randomly chosen from family health care center not included in the sample namely, "Smouha family health care center" in order to ascertain the relevance, clarity and applicability of the tool and test wording of the questions. Based on the obtained results, the necessary modifications were done.

- Data was collected by the researchers during the period from 
October 2015 to December 2015 (3 months).

\section{Ethical considerations:}

- Informed written consents were obtained from the nurses after brief explanation of the purpose and nature of the research.

- The anonymity and confidentiality of responses, voluntary participation and right to refuse to participate in the study were emphasized to nurses. The researchers explained the objectives of the study to the participants.

\section{Statistical Analysis}

After data were collected, they were coded and transferred into specially designed formats so as to be suitable for computer feeding. Following data entry, checking and verification processes were carried out to avoid any errors during data entry, frequency analysis, cross tabulation and manual revision were all used to detect any errors. The statistical package for social sciences (SPSS version 20) was utilized for both data presentation and statistical analysis of the results. Chi square test was used to compare between the groups. The level of significance selected for this study was $\mathrm{P}$ equal to or less than 0.05 .

\section{Results}

Table (1) illustrates the characteristics of the nurses. Regarding the nurses' age, it ranges from 20 to 45 years with a mean of $31.91 \pm 8.83$ years. Half nurses in Alexandria compared to $40.0 \%$ of those nurses at El Behera were aged 40 years and more. The vast majority $(95.0 \%)$ of nurses in $\mathrm{El}$ Behera were married compared to $55.0 \%$ of nurses in Alexandria.

Concerning their educational qualifications, more than half $(60.0 \%$, $54.2 \%$ ) of nurses in Alexandria and El Behera respectively hold bachelor degree. While less than three quarters $(71.3 \%)$ of nurses in Alexandria had more than ten years of experience compared to around one fifth $(19.2 \%)$ of nurses in El Behera governorate. The majority $(86.3 \%, 83.3 \%)$ of nurses in Alexandria and $\mathrm{El} \mathrm{Behera}$ respectively work as staff nurse and more than half of them worked in fixed morning shift $(51.3 \%, 62.5 \%$ respectively).

Moreover, $90.0 \%$ of nurses in El Behera compared to $77.5 \%$ of nurses in Alexandria reported good relationship with coworkers, while the majority $(92.5 \%, 94.2 \%$ respectively) of nurses in both areas reported good relationship with patients. Additionally, the highest percentages of nurses in Alexandria and El Behera reported unavailability of violence preventive strategies such as policies, training, and safety measures $(95.0 \%, \quad 97.5 \%$ respectively).

Table (2) shows that there is no statistically significant difference between nurses in Alexandria and El Behera in relation to exposure to workplace violence $\left(\mathrm{X}^{2}=0.761, \mathrm{P}=0.382\right)$ as $78.8 \%$ of nurses in Alexandria compared to $73.3 \%$ of nurses in El Behera reported exposure to violence in the last year. Verbal abuse was reported by the majority of nurses in Alexandria and El Behera $(92.1 \%, 96.6 \%$ respectively). While $13.6 \%$ of nurses in El Behera compared to more than one third $(39.7 \%)$ of nurses in Alexandria experienced physical violence. On the other hand, sexual harassment was reported by only $3.4 \%$ of nurses in $\mathrm{El}$ Behera compared to one third $(33.3 \%)$ of nurses in Alexandria, with a statistically significant difference between them $\left(\mathrm{X}_{2}^{2}=23.10, \mathrm{P}=0.000\right)$.

The table also reveals that $48.9 \%$ of nurses in El Behera compared to $55.5 \%$ of nurses in Alexandria stated that they exposed to violence three times and more in the last year, and these violent incidents occurred most frequently in the morning shift as mentioned by the majority of nurses in Alexandria and El Behera (84.1\%, 80.7\% respectively). Patients was the first perpetrator of violence against nurses in 
Alexandria and El Behera (69.8\%, 71.6\% respectively), while coworkers' violence was reported by less than one third $(31.7 \%$, $28.4 \%$ ) of nurses in Alexandria and El Behera respectively. Moreover, the majority of nurses in Alexandria and El Behera stated that the perpetrator was male $(85.7 \%$, $86.4 \%$ respectively) and adult of middle age $(85.7 \%, 85.2 \%$ respectively).

The same table indicated that less than two thirds $(60.3 \%, 62.5 \%)$ of nurses in Alexandria and El Behera respectively had no reaction after exposure to violence with a statistically significant difference between them $\left(\mathrm{X}_{3}^{2}=9.893, \mathrm{P}=0.019\right)$. On the other hand, the most common consequences of exposure to violence were psychological effects in form of depression, anxiety and restlessness $(68.3 \%$ of nurses in Alexandria and $70.5 \%$ of nurses in El Behera), followed by work related effects such as absenteeism and poor work performance as reported by more than half $(58.7 \%, 51.1 \%)$ of nurses in Alexandria and El Behera respectively.

Figure (1) portrays that lack of security was the first cause of violence as stated by the majority $(82.5 \%, 88.6 \%)$ of nurses in Alexandria and El Behera respectively. Deficient staff, increased work load and poor resources were reported by $(79.4 \%$, $73.0 \%, 61.9 \%$ respectively) of nurses in Alexandria in comparison to $(73.9 \%$, $81.8 \%, 77.3 \%$ respectively) of nurses in El Behera. Moreover, more than half $(58.7 \%)$ of nurses in Alexandria compared to $42.0 \%$ of nurses in El Behera stated that being a nurse was the cause for their exposure to violence.

Table (3) shows that the lowest percentages $(12.7 \%, 33.0 \%)$ of nurses in Alexandria and El Behera respectively had reported the violent incidents to the health center administrative authority, with a statistically significant difference between them $\left(\mathrm{X}^{2}=8.143, \mathrm{P}=0.004\right)$. Unfortunately, no action was taken by the center authority regarding the majority of the reported incidents in Alexandria and El Behera (87.5\%, 96.6\% respectively). The main causes of not reporting violence incidents was the concept that reporting considered fruitless as stated by the majority $(90.9 \%$, $89.8 \%$ ) of nurses in Alexandria and $\mathrm{El}$ Behera respectively. Lack of knowledge about reporting process was mentioned by $12.7 \%$ of nurses in Alexandria compared to around one fifth $(20.3 \%)$ of nurses in $\mathrm{El}$ Behera.

Figure (2) presents the nurses' suggestions for prevention and control of workplace violence. Availability of security personnel was the most frequent suggestion stated by the majority $(77.5 \%, 80.0 \%)$ of nurses in Alexandria and El Behera respectively. More than half $(51.0 \%, 52.5 \%$ respectively) of nurses in both areas recommend promoting of nurses' qualifications as a measure for control workplace violence. On the other hand, training for violence prevention and management was reported by less than one third $(32.0 \%, 30.0 \%)$ of nurses in Alexandria and El Behera respectively.

Table (4) shows the relation between nurses' personal and occupational characteristics and exposure to workplace violence. The table reveals that the older the age of the nurses, the lesser the violence exposure since it was less encountered among nurses aged forty years and more $(68.8 \%)$ than those aged less than thirty years $(80.4 \%)$, with no statistically significant relation between nurse's age and exposure to violence $\left(\mathrm{X}^{2}=3.033, \mathrm{P}=0.219\right)$.

Moreover, violence exposure was more prevalent among nurses who had a diploma degree $(86.8 \%)$ and worked as a staff nurse $(82.8 \%)$ and among those who had lesser years of experience $(90.2 \%)$. A statistically significant relation was found between each of educational qualifications, job position, years of experience and exposure to violence $\left(\mathrm{X}_{2}^{2}=3.534, \mathrm{P}=0.017, \mathrm{X}_{2}{ }^{2}=8.269\right.$, $\mathrm{P}=0.016, \mathrm{X}^{2}=31.76, \mathrm{P}=0.000$ respectively). Additionally, violence exposure was more encountered among nurses working in chronic diseases' clinic $(81.4 \%)$ and those nurses who worked in rotating shifts 
(83.3\%) with a statistically significant relation was found between type of clinic, type of work shift and violence exposure $\left(\mathrm{X}_{2}^{2}=7.445, \mathrm{P}=0.024, \mathrm{X}^{2}=4.804, \mathrm{P}=0.028\right.$ respectively).

Finally, work place violence was highest $(83.3 \%, 84.6 \%)$ among those nurses who reported poor relationship with coworkers and patients respectively with no significant relation between them $\left(\mathrm{X}^{2}=1.171, \mathrm{P}=0.279\right.$, $\mathrm{X}^{2}=0.624, \mathrm{P}=0.429$ respectively).

\section{Discussion}

Work place violence against health care workers is a common and widespread phenomenon. It is where staffs are abused, threatened, or assaulted in circumstances related to their work, and while commuting to and from work, involved explicit or implicit challenges to their safety, wellbeing or health ${ }^{(15)}$.

Violence affects all work categories and takes place at various settings including primary health care settings ${ }^{(12,13)}$. Nurses as frontline care providers serve in a wide variety of settings caring for individuals who face all type of trauma, suffering, and life altering events ${ }^{(4,8)}$. The result of the present study showed that more than three quarters of nurses experienced workplace violence, which come in accordance with the results of Moustafa $M$ et al. 2013, Algwaiz W et al. 2012, Samir N et al. 2012 and Balamurugan $\mathrm{G}$ et al. $2012^{(1,2,4,16)}$ who found that the majority of nurses had experienced violent incidents at work. This high percentage is not surprising as nurses comprise one of the largest groups in the health care professions, they provide twenty four hours care and they have direct contacts with patients and their relatives, as well as they are confronting all internal and external stresses in the workplace. Therefore, they bear the brunt of patient's disturbed behaviors, the negative physical and psychological impact of the illness and treatment, relatives' dissatisfaction with provided care, and/or the confusing health center rules that externals should abide with. Furthermore, nurses wherever are faced with heavy workloads, conflicts with other professionals, limited clinical autonomy, and non supportive work environment which lead to dissatisfaction; burn out and high rates of turnover and attrition. However, the fact that around three quarters of nurses had experienced aggressive or violent events in their workplaces is alarming and may have an implication for their professional career.

Moreover, the result of the present study indicated that workplace violence was more prevalent in Alexandria than El Behera governorate. This rate of exposure to violence among nurses may be explained by the fact that when patients come to health care institution with different health problems, they seek remedy for their problems. They may have higher expectations of services provided and higher levels of stress and faced with the poor quality of services. This may cause dissatisfaction with the health services and let the patients perceive the health care provider's technical incompetence which may be manifested in the form of using violence against them. Such stress induced violence is exacerbated by living in an environment with a cultural norm that encourages the use of force and violence as a common response to this stress and frustration $^{(17)}$.

Furthermore, lower prevalence of violence in rural areas could be due to the fact that rural people tends to be loyal, familiar with each other, forgiving, religious, having more peaceful as well as calming environment which may consequently have an impact on calming person's moods ${ }^{(18)}$. So, the violent incidents may be situational rather than habitual. In the same line, Almalki M et al. 2012 and Newman C et al. 2008 ${ }^{(13,19)}$ who found that health care workers in urban areas experienced more violence than those working in rural areas.

The fact that the majority of nurses were exposed to some type of violence is a 
matter of concern. According to the nurses' perceived reasons for violence, the high level of violence against them can be explained by the current state of governmental health services including understaffing and inadequate working conditions, delays in receiving care as well as unmet patient needs or expectations, workload, and lack of information, education and communication regarding workplace violence. Furthermore, this situation is exacerbated, as the study results indicated, by lack of violence preventing strategies such as policy, training, and lack of adequate safety measures to protect health workers from violence in health facilities. Evidence from other studies showed that such conditions and factors can result in violence against nurses ${ }^{(1,2,4,13)}$.

Based on the finding of the present study, verbal violence was the most common type of violence experienced by the vast majority of nurses in rural and urban areas, followed by physical violence This is consistent with the results of Moustafa M et al. 2013, Abbas M et al. 2010, Balamurugan $\mathrm{G}$ et al. 2012 and Farouk H $2011^{(1,7,16,20)}$ who found that verbal abuse occurred more frequently than physical abuse. However, because verbal violence is the most experienced form of violence, verbal communications skills to calm patients and visitors and to create a friendly environment seem to be very important for prevention and de-escalation.

Moreover, the less prevalent type of workplace violence was sexual harassment. This may be due to the fact that sexual assaults and harassment are unacceptable behaviors in our community and contradicte with the law and religious practices. This is supported by the results of Sepctor P et al. 2014 and Abbas M et al. 2010

Furthermore, the present study found that physical violence and sexual harassment were more encountered among nurses working in urban areas. This could be attributed to the cultural differences between urban and rural communities.
Urban community is considered a high risk environment for violence, as it witness the convergence of many risk factors for violence. So, violence may be more prevalent in urban areas than rural one ${ }^{(14,17)}$. This is consistent with the results of Almalki M et al. 2012 and Newman C et al. $2008^{(13,19)}$.

From the results of the present study, it is observed that more than half of the nurses experienced three and more violent attacks in the last year, and these assaults were more likely to occur in the morning shift. Similar results were reported by Moustafa M et al. 2013 Abbas M et al. 2010, Kitaneh M et al. 2012 and Samir A $2012^{(1,7,9,21)}$ who found that most violent events occurred in early working hours. Higher rates of violence during this time can be attributed to shortening of nursing staff, non supportive work environment, over loaded work demands, overcrowding and long waiting times in family health care centers that place stress on human resources which would also increase conflicts with patients and health care providers especially nurses.

Similar to other studies, the patients and their relatives were frequently reported as the main perpetrator of violence toward nurses $^{(6,7,9,15,19,22)}$. This could be explained as nurses are usually the first person that patients and their families meet. Therefore, they are often blamed for late or inadequate health services as patients are often afraid that a physician may refuse to care for and treat them properly if they blame the doctors. In effect, nurses become the escape goat $^{(21)}$. Further, nurses who find themselves short staffed, forced to rush care, increase the dissatisfaction of patients and their families from the care they receive so increasing the likelihood of workplace violence.

Nevertheless, a matter of concern was the proportion of violence created by colleagues and supervisors as around one quarter of nurses reported experiencing violent incidents from their coworkers especially physicians. This is contrary to 
expectations, as ideally, health care setting should be free from violent threats and workers should work in a cooperative manner that provides a safe environment for both patients and the coworkers themselves. But, understaffing, job stress, low job satisfaction are among possible factors that might lead to aggression towards colleagues and coworkers. In the same context, the results of Samir N et al. 2012, Kitaneh M et al. 2012 and Farouk H 2011 $1^{(4,9,20)}$ who found that physicians and supervisors were the third source of work place violence against nurses.

It is worth mentioning that workplace violence was mainly perpetrated by male and those of middle age. Available evidences showed that there are biological dimensions to the age- sex- violence relationship. Aging has biological, neurological, psychological and social aspects, as it set the parameters of possibility and limitation for behaviors including violent behaviors. Hormones levels play an important role in violence perpetration as testosterone levels peak in early adulthood, which is an important cause of violence and aggression, which explain why men commit more violence acts than women. Moreover, men are more likely and physically capable of enacting violence against women. In addition to this, women tend more to respond to stress with "tend and befriend" method, while men tend more to act out "fight and flight" responses ${ }^{(23,24)}$. This finding is supported by several studies as Moustafa M et al. 2013, Abbas M et al. 2010 and Kitaneh $\mathrm{M}$ et al. $2012^{(1,7,9)}$ which found men committed more physical and sexual violent incidents while women committed more verbal and psychological violent incidents.

Nurses' exposure to workplace violence should be alarming because of its short and long term effects on the nurses' physical, psychological, social status and professional performance. This was reflected in the present study results where most of the nurses reported psychological effects such as anger, fear, depression, stress and frustration, while more than half of nurses reported subsequent changes in their work status including restrictions in work, absence from work and decreased work performance and efficiency which have significant implication on the quality of care provided. Attention should be given to violence deterrent policies and measures at the workplace as well as enforcement of the legal system after such events. The same consequences were reported by Algwaise $\mathrm{W}$ et al. 2012, Taylor L et al. 2011 and Rajbhandari R et al. $2015^{(2,5,8)}$.

Individuals vary in their reaction to violence exposure. They may use their experience and training to defuse, control the situation or physically react to such conflict. Alternatively, they may overcome the incidence by fear or panic or react in a manner that inflames the situation. An individual's innate personality traits plus context and environment act as influential factors in establishing the persons' response $^{(25)}$. This could explain the result of the present study, as less than two thirds of nurses had no reaction to violence exposure. Similar findings were reported by Spector P et al. 2014, Farouk H 2011 and Samir A $2012^{(6,20,21)}$. It may be attributed to the fact that nursing is a caring profession and it is the nurse role to manage the violence provoking incidents. Nurses are taught to put the patients' needs first and to recognize and sympathize with the patient's stresses that may trigger violence.

Accordingly, underreporting of violent incidents is common; this was reflected in the current study as less than one quarter of violent incidents was reported by nurses. The nurses attributed their reluctance to report due to lack of clear procedure of reporting and management, beside the fear of negative consequences such as blame or revenge of perpetrators. Therefore, they tolerate the assailant, and do not feel that they should support the events. This is consistent with the high rate of under reporting identified by other 
studies $^{(1,6,10,19,21,26)}$. The lack of procedure for reporting, investigation of assault to nurses in this study is of great concern. Standardized reporting procedure by managements would help to provide a more objective and the true picture of violence.

Certain characteristics have been found to increase the risk of nurses being targets of workplace violence in the health care settings including the nurse's age, years of experience, educational qualifications, job position, type of clinic, and relationship with patients and co workers.

Regarding the nurse's age, the result of the present study indicated that as the age of the nurse increased, the violence committed against them decreased. This come in line with the results of Balmurugan $G$ et al. 2012, Magnavita N 2012 and Fute M et al. $2015^{(16,22,27)}$. This might be due to young nurses' lack of ability and experience in dealing with violence, and inadequate safety measures. In addition, this might partly be explained that older people including health care providers receive due respect in the Egyptian culture and perhaps elsewhere.

Moreover, the current study revealed that those nurses with lower educational level and worked as staff nurses experienced higher incidents of workplace violence which comes in line with the results of Farouk H 2011, Fute $M$ et al. 2015 and El Houfey A et al. 2015 $20,27,28)$. This could be attributed to that staff nurses are the primary care providers of patients, so they have a close contact with patients and their relatives. Or due to the way they treated patients as they may missed some skills and knowledge needed to provide more competent high quality care.

In addition, the results of the present study indicated that nurses with less work experience years reported a greater exposure to violent attacks. This result is consistent with the findings of Moustafa M et al. 2013, Samir N et al. 2012 and Rajbhandari R 2015 who found that nurses who had one to five years of experience had higher risk of experiencing workplace violence $^{(1,4,8)}$. This might be due to the fact that nurses with shorter services years had less experience in dealing or preventing various types of violent provoking situations and could not dissolve the possibility of violence promptly.

Furthermore, the result of the present study showed that nurses working in medical/chronic diseases clinics experienced more violence than those in other clinics. This may explained by the nature of the population that the nurse had to care for as chronic diseases permanently changes the person's life either by the demanding set of lifelong self-care management or by its devastating complications which have an impact on a patient's quality of life ${ }^{(29)}$. Those patients may experience high levels of emotional stress, frustration, anxiety, or anger stemming from concerns and worries associated with their disease and its management which that may manifest itself in problematic interactions with nursing staff, aggressive behavior and a higher occurrence of violence. This is supported by the results of Abodunrin O 2014, Hahn S et al. 2012, and Sheilds M et al. 2009 who found that work place violence was most often experienced by nurses working in intensive care unit, emergency room and medical unit ${ }^{(30,31,32)}$.

The result of the present study indicated that exposure to violence was more encountered among those nurses with poor relation with supervisors, physicians, colleagues and patients. Such disturbed relations could be direct consequence for being exposed to violence or it could be the trigger for exposure to violence. Chicken egg dilemma exists and needs further comprehensive research. This is consistent with the results of Moustafa M et al. 2013, Hahn S et al. 2012, Moustafa S 2011 and Hahn $S$ et al. 2010 who found that poor relationship with colleagues and patients are triggering factors for violence ${ }^{(1,31,33,34)}$. 


\section{Conclusion}

Based upon the findings of the current study it could be concluded that a significant proportion of nurses faced verbal violence while providing care in primary health care facilities in the twp governorates. No significant difference was found between nurses in Alexandria and El Behera governorates in relation to their exposure to workplace violence. Being staff nurse, younger age, and short work experience were significantly associated with workplace violence.

\section{Recommendations}

Recommendations directed to Ministry of Health and Population:

- Implement policies for punishing workplace violence and create mechanisms for them to be enforced.

- Develop effective guidelines to avoid workplace violence and protect nursing staff such as a mandatory incident reporting system, review of security teams' responsibilities, and incident follow-up by management.

- Nurses need to know how and to whom to report as well as how to document problem situations. Nurses should be reassured that reporting threatening behavior will not result in reprisals and that appropriate action will be taken to deal with abusers.

- Training programs for nurses are recommended that focus on communication techniques and stress or anger management with conflict resolution to effectively manage violence in the workplace especially for younger age nurses, and those with short work experience.

- The health facilities should also establish health and safety programs for the prevention and management of workplace violence.
- The services in the healthcare facility should also be improved and supported with the required materials and equipment and security departments.

- A safe and secure employment environment is an irrefutable right of all nurses and is essential for the provision of quality care.

\section{Recommendations directed to Ministry of} Higher Education:

- It is worthwhile to disclose the issues of violent clients in the early nursing education at university. Giving students the opportunity to acquaint themselves with this issue and reflect upon it can increase their capability to deal with such events in their future practice.

\section{Recommendations directed to Media:}

- Primary health care managers should work with the media to demonstrate the vital role of nurses in the care of the community, in the provision of health care services and in the advancement of the health of the population.

\section{Recommendations for further research:}

- Further research is required to develop the appropriate assessment tool and maintenance guidelines, to use it in various situations. 
Table (1): Distribution of nurses according to their personal and socio demographic characteristics

\begin{tabular}{|c|c|c|c|c|c|c|}
\hline \multirow[t]{2}{*}{ Nurses' Characteristics } & \multicolumn{2}{|c|}{$\begin{array}{c}\text { Alexandria } \\
(N=80)\end{array}$} & \multicolumn{2}{|c|}{$\begin{array}{l}\text { El Behera } \\
(\mathrm{N}=120)\end{array}$} & \multicolumn{2}{|c|}{$\begin{array}{c}\text { Total } \\
(\mathrm{N}=200)\end{array}$} \\
\hline & No & $\%$ & No & $\%$ & No & $\%$ \\
\hline \multicolumn{7}{|l|}{ Age (years) } \\
\hline$-20-$ & 11 & 13.7 & 35 & 29.2 & 46 & 23.0 \\
\hline$-30-$ & 40 & 36.3 & 37 & 30.8 & 77 & 38.5 \\
\hline \multirow[t]{2}{*}{$-40+$} & 29 & 50.0 & 48 & 40.0 & 77 & 38.5 \\
\hline & \multicolumn{2}{|c|}{$\begin{array}{c}\mathrm{X} \pm \mathrm{SD} \\
33.90 \pm 5.25\end{array}$} & \multicolumn{2}{|c|}{$\begin{array}{c}\mathrm{X} \pm \mathrm{SD} \\
35.92 \pm 8.46\end{array}$} & \multicolumn{2}{|c|}{$\begin{array}{c}\mathrm{X} \pm \mathrm{SD} \\
37.91 \pm 8.83\end{array}$} \\
\hline \multicolumn{7}{|l|}{ Marital status } \\
\hline - Married & 44 & 55.0 & 114 & 95.0 & 158 & 79.0 \\
\hline - Not married (single- widowed- divorced) & 36 & 45.0 & 6 & 5.0 & 42 & 21.0 \\
\hline \multicolumn{7}{|l|}{ Educational qualifications } \\
\hline - Diploma degree & 11 & 13.7 & 27 & 22.5 & 38 & 19.0 \\
\hline - Associate degree & 21 & 26.3 & 28 & 23.3 & 49 & 24.5 \\
\hline - Bachelor degree & 48 & 60.0 & 65 & 54.2 & 113 & 56.5 \\
\hline \multicolumn{7}{|l|}{ Years of experience } \\
\hline$-1-$ & 16 & 20.0 & 35 & 29.1 & 51 & 25.5 \\
\hline$-6-$ & 7 & 8.7 & 62 & 51.7 & 69 & 34.5 \\
\hline \multirow[t]{2}{*}{$-11+$} & 57 & 71.3 & 23 & 19.2 & 80 & 40.0 \\
\hline & \multicolumn{2}{|c|}{$\begin{array}{c}\mathrm{X} \pm \mathrm{SD} \\
14.34 \pm 8.62\end{array}$} & \multicolumn{2}{|c|}{$\begin{array}{c}\mathrm{X} \pm \mathrm{SD} \\
9.57 \pm 4.58\end{array}$} & \multicolumn{2}{|c|}{$\begin{array}{c}\mathrm{X} \pm \mathrm{SD} \\
11.58 \pm 8.77\end{array}$} \\
\hline \multicolumn{7}{|l|}{ Current job position } \\
\hline - Staff nurse & 69 & 86.3 & 100 & 83.3 & 169 & 84.5 \\
\hline - Head/ Charge nurse & 11 & 13.7 & 20 & 16.7 & 31 & 15.5 \\
\hline \multicolumn{7}{|l|}{ Type of clinic / current specialty } \\
\hline - Obstetric / Family planning clinic & 31 & 38.7 & 42 & 35.0 & 73 & 36.5 \\
\hline - Pediatric / Vaccination clinic & 26 & 32.5 & 42 & 35.0 & 68 & 34.0 \\
\hline - Chronic diseases clinic & 23 & 28.8 & 36 & 30.0 & 59 & 29.5 \\
\hline \multicolumn{7}{|l|}{ Type of work rotation } \\
\hline - Fixed shift & 41 & 51.3 & 75 & 62.5 & 116 & 58.0 \\
\hline - Rotating shift & 39 & 48.7 & 45 & 37.5 & 84 & 42.0 \\
\hline \multicolumn{7}{|c|}{ Relation with coworkers (supervisors - physicians - colleagues) } \\
\hline - Good & 62 & 77.5 & 108 & 90.0 & 170 & 85.0 \\
\hline - Poor & 18 & 22.5 & 12 & 10.0 & 30 & 15.0 \\
\hline \multicolumn{7}{|l|}{ Relation with patients } \\
\hline - Good & 74 & 92.5 & 113 & 94.2 & 187 & 93.5 \\
\hline - Poor & 6 & 7.5 & 7 & 5.8 & 13 & 6.5 \\
\hline \multicolumn{7}{|l|}{ Availability of violence prevention strategies } \\
\hline - Yes & 4 & 5.0 & 3 & 2.5 & 7 & 3.5 \\
\hline - No & 76 & 95.0 & 117 & 97.5 & 193 & 96.5 \\
\hline
\end{tabular}


Table (2): Distribution of the nurses according to their experience of workplace violence

\begin{tabular}{|c|c|c|c|c|c|}
\hline \multirow[t]{2}{*}{$\begin{array}{l}\text { Items } \\
\end{array}$} & \multicolumn{2}{|c|}{$\begin{array}{c}\text { Alexandria } \\
(\mathrm{N}=80)\end{array}$} & \multicolumn{2}{|c|}{$\begin{array}{c}\text { El Behera } \\
(\mathrm{N}=120)\end{array}$} & \multirow[t]{2}{*}{$\begin{array}{c}\text { Test of } \\
\text { significance }\end{array}$} \\
\hline & No & $\%$ & No & $\%$ & \\
\hline \multicolumn{6}{|l|}{ Workplace violence exposure } \\
\hline - Yes & 63 & 78.8 & 88 & 73.3 & $X^{2}=0.761$ \\
\hline - No & 17 & 21.2 & 32 & 26.7 & $\mathrm{P}=0.382$ \\
\hline Type of workplace violence* & \multicolumn{2}{|c|}{$N=63$} & \multicolumn{2}{|c|}{$\mathrm{N}=\mathbf{8 8}$} & \\
\hline - Verbal & 58 & 92.1 & 85 & 96.6 & $\mathrm{X}_{2}^{2}=23.10$ \\
\hline - Physical & 25 & 39.7 & 12 & 13.6 & $\mathrm{P}=0.000^{* *}$ \\
\hline - Sexual & 21 & 33.3 & 3 & 3.4 & \\
\hline \multicolumn{6}{|l|}{ Frequency of exposure to workplace violence } \\
\hline - Once & 10 & 15.9 & 21 & 23.9 & $\mathrm{X}_{2}^{2}=1.482$ \\
\hline - Twice & 18 & 28.6 & 24 & 27.3 & $\mathrm{P}=0.476$ \\
\hline - Three times or more & 35 & 55.5 & 43 & 48.9 & \\
\hline \multicolumn{6}{|l|}{ Time of exposure to workplace violence* } \\
\hline - Morning & 53 & 84.1 & 71 & 80.7 & $\mathrm{X}_{2}^{2}=0.837$ \\
\hline - Evening & 28 & 44.4 & 34 & 38.6 & $\mathrm{P}=0.657$ \\
\hline - Both & 18 & 28.6 & 17 & 19.3 & \\
\hline \multicolumn{6}{|l|}{ Perpetrator of workplace violence* } \\
\hline - Patients / clients & 44 & 69.8 & 63 & 71.6 & $\mathrm{X}_{2}^{2}=0.180$ \\
\hline - Patients relatives & 31 & 49.2 & 45 & 51.1 & $\mathrm{P}=0.913$ \\
\hline - Coworkers (supervisors, physicians, nurses) & 20 & 31.7 & 25 & 28.4 & \\
\hline \multicolumn{6}{|l|}{ Sex of perpetrators* } \\
\hline - Male & 54 & 85.7 & 76 & 86.4 & $X^{2}=0.122$ \\
\hline - Female & 32 & 50.8 & 43 & 48.9 & $P=0.726$ \\
\hline \multicolumn{6}{|l|}{ Ag group of perpetrator* } \\
\hline - Child / Adolescent & 6 & 9.5 & 8 & 9.1 & $\mathrm{X}_{2}^{2}=0.052$ \\
\hline - Adult & 54 & 85.7 & 75 & 85.2 & $\mathrm{P}=0.974$ \\
\hline - Elderly & 21 & 33.3 & 27 & 30.7 & \\
\hline \multicolumn{6}{|l|}{ Immediate reaction to workplace violence* } \\
\hline - No reaction & 38 & 60.3 & 55 & 62.5 & $\mathrm{X}_{3}^{2}=9.893$ \\
\hline - Call for help & 5 & 6.3 & 7 & 7.9 & $\mathrm{P}=0.019 * *$ \\
\hline - Defend verbally & 11 & 17.5 & 5 & 5.7 & \\
\hline - Defend physically & 9 & 14.3 & 2 & 2.3 & \\
\hline \multicolumn{6}{|l|}{ Consequences of workplace violence* } \\
\hline - Psychological effect & 43 & 68.3 & 62 & 70.5 & $\mathrm{X}_{2}^{2}=1.903$ \\
\hline - Physical effect & 12 & 19.0 & 9 & 10.2 & $\mathrm{P}=0.386$ \\
\hline - Work related effect & 37 & 58.7 & 45 & 51.1 & \\
\hline
\end{tabular}

* Multiple answers were allowed 


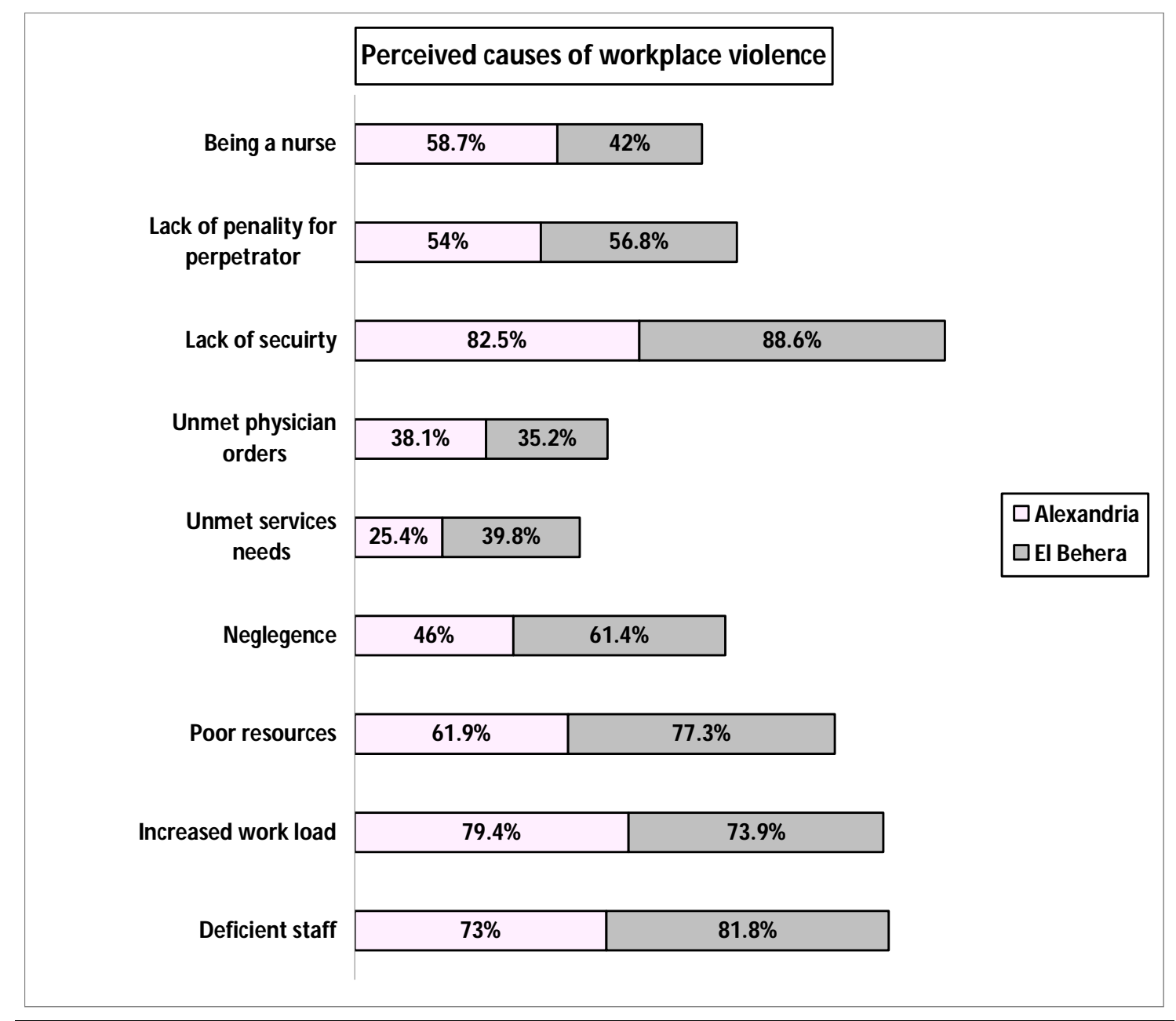

* Multiple answers were allowed

Figure (1): Causes of workplace violence* 
Table (3): Distribution of the nurses according to their reporting incidents of workplace violence

\begin{tabular}{|c|c|c|c|c|c|}
\hline \multirow[t]{2}{*}{ Items } & \multicolumn{2}{|c|}{$\begin{array}{l}\text { Alexandria } \\
(\mathrm{N}=63)\end{array}$} & \multicolumn{2}{|c|}{$\begin{array}{c}\text { El Behera } \\
(\mathrm{N}=88)\end{array}$} & \multirow[t]{2}{*}{$\begin{array}{c}\text { Test of } \\
\text { significance }\end{array}$} \\
\hline & No & $\%$ & No & $\%$ & \\
\hline \multicolumn{6}{|l|}{ Reporting of workplace violence incidents } \\
\hline- Yes & 8 & 12.7 & 29 & 33.0 & $\mathrm{X}^{2}=8.143$ \\
\hline - No & 55 & 87.3 & 59 & 67.0 & $\mathrm{P}=0.004 * *$ \\
\hline Causes of not reporting * & \multicolumn{2}{|c|}{$\mathrm{N}=\mathbf{5 5}$} & \multicolumn{2}{|c|}{$\mathbf{N}=\mathbf{5 9}$} & \\
\hline - Reporting considered fruitless & 50 & 90.9 & 53 & 89.8 & $\mathrm{X}_{4}^{2}=1.034$ \\
\hline - Fear of negative consequences & 41 & 74.5 & 42 & 71.2 & $\mathrm{P}=0.904$ \\
\hline - Felt ashamed & 34 & 61.8 & 36 & 61.0 & \\
\hline - No harm intended & 23 & 41.8 & 25 & 42.4 & \\
\hline - Lack of knowledge about reporting process & 7 & 12.7 & 12 & 20.3 & \\
\hline Action taken by health center authority & \multicolumn{2}{|c|}{$\mathbf{N}=\mathbf{8}$} & \multicolumn{2}{|c|}{$\mathbf{N}=\mathbf{2 9}$} & \\
\hline - Investigating the incident & 1 & 12.5 & 1 & 3.4 & $\mathrm{X}^{2}=1.005$ \\
\hline - No action & 7 & 87.5 & 28 & 96.6 & $\mathrm{P}=0.316$ \\
\hline
\end{tabular}

* Multiple answers were allowed

** Significant at $\mathrm{P} \leq 0.05$

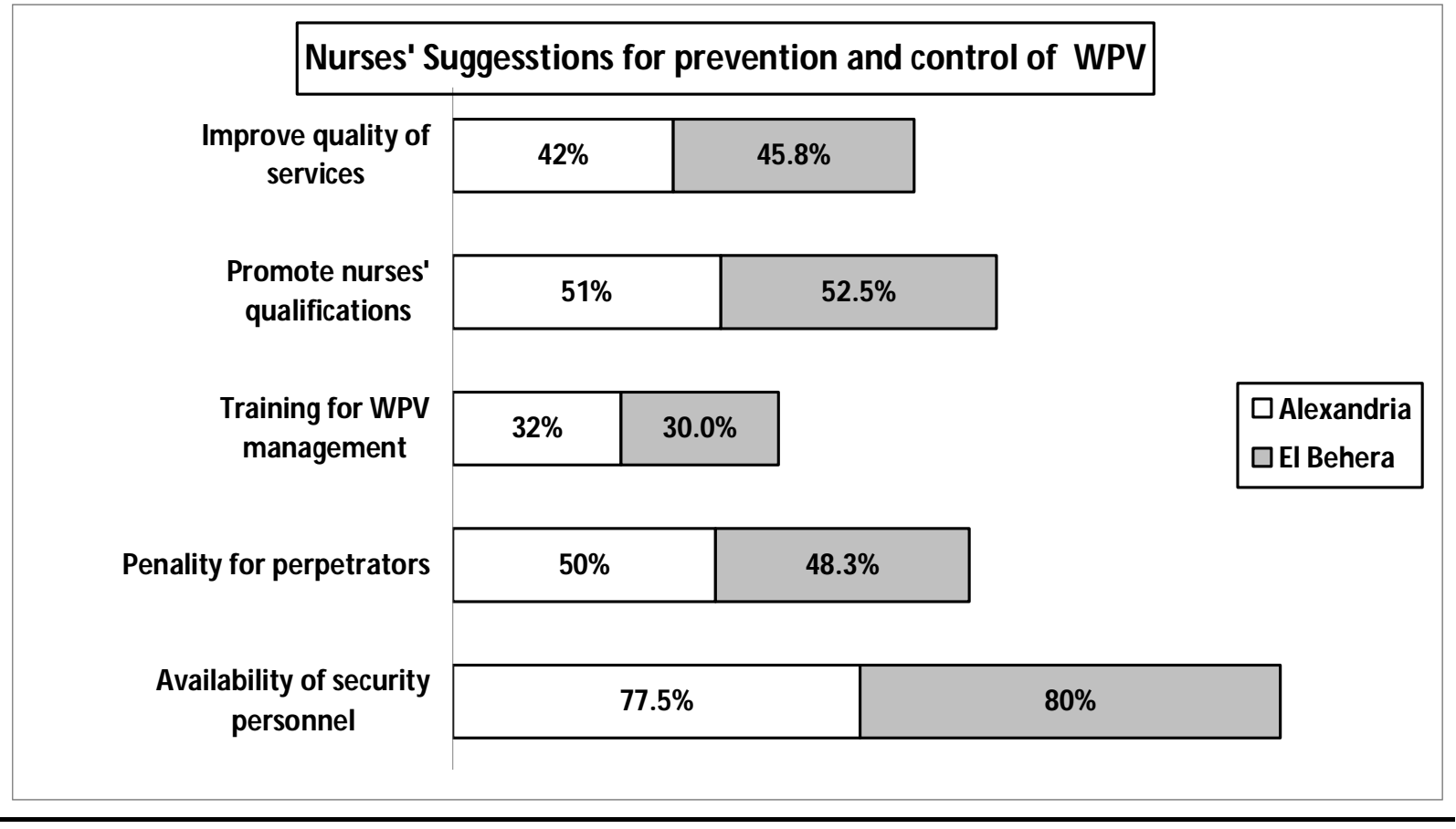

* Multiple answers were allowed

Figure (2): Nurses' suggestions for prevention and control of workplace violence* 
Table (4): The relation between the nurses' exposure to workplace violence and their personal and occupational characteristics

\begin{tabular}{|c|c|c|c|c|c|}
\hline \multirow[t]{3}{*}{ Nurses' characteristics } & \multicolumn{4}{|c|}{ Violence exposure } & \multirow{3}{*}{$\begin{array}{c}\text { Test of } \\
\text { Significance }\end{array}$} \\
\hline & \multicolumn{2}{|c|}{$\begin{array}{c}\text { Yes } \\
(\mathrm{N}=151)\end{array}$} & \multicolumn{2}{|c|}{$\begin{array}{c}\text { No } \\
(\mathrm{N}=49)\end{array}$} & \\
\hline & No & $\%$ & No & $\%$ & \\
\hline \multicolumn{6}{|l|}{ Age (years) } \\
\hline$-20-$ & 37 & 80.4 & 9 & 19.6 & $\mathrm{X}_{2}^{2}=3.033$ \\
\hline$-30-$ & 61 & 79.2 & 16 & 20.8 & $\mathrm{P}=0.219$ \\
\hline$-40+$ & 53 & 68.8 & 24 & 31.2 & \\
\hline \multicolumn{6}{|l|}{ Marital status } \\
\hline - Married & 124 & 78.5 & 34 & 21.5 & $X^{2}=3.615$ \\
\hline $\begin{array}{l}\text { - Not married (single- widowed- } \\
\text { divorced) }\end{array}$ & 27 & 64.3 & 15 & 35.7 & $\mathrm{P}=0.057$ \\
\hline \multicolumn{6}{|l|}{ Educational qualifications } \\
\hline - Diploma degree & 33 & 86.8 & 5 & 13.2 & $\mathrm{X}_{2}^{2}=3.534$ \\
\hline - Associate degree & 37 & 75.5 & 12 & 24.5 & $\mathrm{P}=0.017 * *$ \\
\hline - Bachelor degree & 81 & 71.7 & 32 & 28.3 & \\
\hline \multicolumn{6}{|l|}{ Years of experience } \\
\hline$-1-5$ & 46 & 90.2 & 5 & 9.8 & $\mathrm{X}_{2}^{2}=8.269$ \\
\hline$-6-10$ & 50 & 72.5 & 19 & 27.5 & $\mathrm{P}=0.016^{* *}$ \\
\hline$-11+$ & 55 & 68.8 & 25 & 31.2 & \\
\hline \multicolumn{6}{|l|}{ Current job position } \\
\hline - Staff nurse & 140 & 82.8 & 29 & 17.2 & $X^{2}=31.76$ \\
\hline - Head/ Charge nurse & 11 & 35.5 & 20 & 64.5 & $\mathrm{P}=0.000 * *$ \\
\hline \multicolumn{6}{|l|}{ Type of clinic / current specialty } \\
\hline - Obstetric / Family planning clinic & 52 & 71.2 & 21 & 28.8 & $\mathrm{X}_{2}^{2}=7.445$ \\
\hline - Pediatric / Vaccination clinic & 51 & 75.0 & 17 & 25.0 & $\mathrm{P}=0.024 * *$ \\
\hline - Chronic diseases clinic (medical) & 48 & 81.4 & 11 & 18.6 & \\
\hline \multicolumn{6}{|l|}{ Type of work rotation } \\
\hline - Fixed shift & 81 & 69.8 & 35 & 30.2 & $X^{2}=4.804$ \\
\hline - Rotating shift & 70 & 83.3 & 14 & 16.7 & $\mathrm{P}=0.028^{* *}$ \\
\hline \multicolumn{6}{|l|}{ Relation with coworkers } \\
\hline - Good & 126 & 74.1 & 44 & 25.9 & $X^{2}=1.171$ \\
\hline - Poor & 25 & 83.3 & 5 & 16.7 & $\mathrm{P}=0.279$ \\
\hline \multicolumn{6}{|l|}{ Relation with patients } \\
\hline - Good & 140 & 74.9 & 47 & 25.1 & $X^{2}=0.624$ \\
\hline - Poor & 11 & 84.6 & 2 & 15.4 & $\mathrm{P}=0.429$ \\
\hline
\end{tabular}

** Significant at $\mathrm{P} \leq 0.05$ 


\section{References}

1. Moustafa M, Gowaifel G. WorkRelated Violence among Female Employees in a University Hospital in Alexandria: An Epidemiologic Study. Journal of American Science 2013; 9(3):243-50.

2. Algwaise W, Alghanim S. Violence exposure among health care professionals in Saudi public hospitals: A preliminary investigation. Saudi Medical Journal 2012; 33(1):76-82.

3. Merecz D, Rymanzewsk J, Mocicka A, Kiejna A, Nowak J. Violence at the workplace: A questionnaire survey of nurses. European Psychiatry 2006; 21:442-50.

4. Samir N, Mohamed R, Moustafa E, Abou Saif H. Nurses' attitudes and reactions to workplace violence in obstetrics and gynecology departments in Cairo hospitals. Eastern Mediterranean Health Journal 2012; 18(3): 198-204.

5. Taylor J, Rew L. A Systematic review of the literature. Workplace violence in the emergency department. Journal of Clinical Nursing 2011; 20:1072-85.

6. Spector P, Zhou Z, Che X. Nurses exposure to physical and non physical violence, bulling, and sexual harassment: A quantitative review. International Journal of Nursing Studies 2014; 51: 72-84.

7. Abbas M, Fiala L, Abdel Rahman A, Fahim A. Epidemiology of Workplace Violence against Nursing Staff in Ismailia Governorate, Egypt. J Egypt Public Health Assoc 2010; 85(1):30- 45.

8. Rajbhandari R, Subedi S, Kaphle H. Workplace Violence against Health Workers: A Cross-Sectional Study from Baglung District, Nepal. International
Journal of Health Sciences \& Research 2015; 5(2): 274-80.

9. Kitaneh M, Hamdan M. Workplace violence against physicians and nurses in Palestinian public hospitals: A CrossSectional Study. BMC Health Services Research 2012; 12: 1-9.

10. Talas M, Kocaöz S, Akgüç S. A Survey of Violence against Staff Working in the Emergency Department in Ankara, Turkey. Asian Nursing Research 2011; 5: 197-203.

11. Gillespie G, Gates D, Miller M, Howard P. Workplace Violence in Health Care Settings: Risk Factors and Protective Strategies. Rehabilitation Nursing 2010; 35(5): 177-84.

12. El-Guilany A, El-Wehady A, Amr N. Violence against primary health care workers in El-Hassa, Saudi Arabia. Journal of Interpersonal Violence 2010; 25 (4): 716-34.

13. Almalki M, Gerald G, Clark M. Quality of Work life among primary health care nurses in the Jazan region, Saudi Arabia: A Cross-Sectional Study. Human Resources Health Journal 2012; 10: 30-40.

14. Zamanzadeh V, Anthony D. Barriers to nursing job motivation. Research Journal of Biological Sciences 2008; 3(4):426-34.

15. Khademloo M, Moonesi F, Gholizade H. Health Care Violence and Abuse towards Nurses in Hospitals in North of Iran. Global Journal of Health Sciences 2013; 5(4):211-6.

16. Balamurugan G, Joseb T, Nandakumar P. Patients' violence towards nurses: A questionnaire survey. International Journal of Nursing 2012; 1(1): 1-7. 
17. The World Bank. Violence in the City: Understanding and Supporting Community Responses to Urban Violence. $1^{\text {st }}$ ed; The World Bank: Washington, 2011. Available at http://www.worldbank.org. Retrieved on: December 2015.

18. Marcia S, Jeanette L. Public Health Nursing: Population Centered Health Care in The Community. ${ }^{7 \text { th }}$ ed; Mosby: Canada, 2008.

19. Newman C, Kanakuze J, Finne A. Study on workplace violence within the health sector in Rwanda.2008. Available at http://www.capacityproject.org.

Retrieved on: August 2015.

20. Farouk H. Prevalence of Workplace Violence toward Health Care Providers. Master thesis, Faculty of Nursing, Alexandria University, Egypt, 2011.

21. Samir A. Verbal and physical violence against Jordanian nurses in the work environment. Eastern Mediterranean Health Journal 2012; 18(4): 318-24.

22. Magnavita N, Heponiemi T. Violence towards health care workers in a Public Health Care Facility in Italy: a repeated cross-sectional study.BMC Health Services Research 2012; 12:108-17.

23. Patricia G, Winifred Z, Kaien A. Psychiatric Mental Health Nursing: An introduction to theory and practice. $7^{\text {th }}$ ed. Jones and Beatle Publisher: Boston, 2008.

24. Ashley L, Backé H, Bates M, Charlebois M, Duffley L, Foster B, et al. Public health community health nursing practices in Canada: role and activities. $4^{\text {th }}$ ed. Canadian Public Health Association; 2010.

25. Stanhope M, Lancaster T. Public Health Nursing: Population centered health care in the community. 7th ed. USA: Mosby Company; 2008.

26. Franz S, Zeh A, Schablon A, Kuhnert S, Neinhaus A. Aggression and violence against health care workers in GermanyA cross sectional retrospective survey. BMC Health Services Research 2010; 10: 1-8.

27. Fute M, Birhanu Z, Wakgri N, Tessam G. High prevalence of workplace violence among nurses working in public health facilities in Southern Ethiopia. BMC Nursing 2015; 14(9): 15.

28. El Houfey A, Abo El Maged N, Elserogy Y, El Ansari W. Workplace Bulling Against Medical and Nursing Team Working At Emergency Departments in Assiut University Hospital. IOSR Journal of Nursing and Health Science 2015; 4(2): 1-9.

29. Al Omari H. Physical and verbal workplace against nurses in Jordan. International Nursing Review 2015; 62(1): 111-8.

30. Abodunrin O, Adeoye O, Adeomi A, Akande T. Prevalence and forms of violence against health care professionals in a South-Western city, Nigeria. Journal of Medicine and Medical Sciences 2014; 2(8): 67-72.

31. Hahn S, Hantikainen V, Needham I, Kok G, Dassen T. Patient and visitor violence in the general hospital, occurrence, staff interventions and consequences: a cross-sectional survey. Journal of Advanced Nursing 2012; 68(12): 2685-99.

32. Shields M, Wilkins K. Factors related to job abuse of nurses by patients. Health Reports 2009; 20(2): 7-19. 
33. Moustafa S. Relationship between Workplace Violence and Nursing Job Satisfaction. Master thesis, Faculty of Nursing, Alexandria University, Egypt, 2011.

34. Hahn S, Müller M, Needham I, Kok G, Dassen T, Halfens R. Factors associated with patient and visitor violence experienced by nurses in general hospitals in Switzerland: A crosssectional survey. Journal of Clinical Nursing 2010; 19: 3535- 46. 